\title{
LA FUNCIÓN IDEOLÓGICA DE LAS REVISTAS CULTURALES ÁRABES CONTEMPORÁNEAS
}

\author{
MJosé Rebollo Ávalos \\ Universidad de Extremadura
}

\begin{abstract}
Halfway through the XXth Century distinguished arab writers, joúrnalists and politicians used the pages of magazines of ideological and cultural content to dernand their national independence. Since then, although linked to the leading political power, their pages were useful for intellectuals to go into their essence, to show their "arabidad" and to provide the arab conciousness with more strength and a deeper identity. One should not forget that the aforernentioned conciousness was strongly influenced by the West. Said rnagazines have been following the ideological points of the arab nationalisrn.
\end{abstract}

La difusión de revistas de contenido ideológico y cultural en destacados países árabes como Egipto, Siria, Iraq, Líbano... adquiere una importancia relevante a partir de los años cincuenta, tras el fin del colonialismo francés e inglés. Periodistas, escritores y políticos se sirvieron de ellas para reivindicar la independencia nacional.

La experiencia colonialista vivida por estos países les mostró la necesidad de profundizar en su propia conciencia. Y así, estas públicaciones gozaron de gran aceptación en los círculos intelectuales árabes, que vieron en ellas un vehículo para entablar un diálogo entre sí en tomo a asuntos claves cuyas repercusiones compartían. Cuestiones como nacionalismo, socialismo, progreso, orgullo nacional, unidad e identidad sobresalen especialmente en estas revistas. El sionismo, la cuestión de Palestina, la influencia de Occidente, sentimientos de vergüenza, impotencia, pero también una intensa fuerza combativa y revolucionaria son referencias repetidas en muchos artículos. Junto a ello estas publicaciones muestran también una realidad cultural propia que se refleja en distintos campos artísticos, científicos y técnicos. En unos y otros subyace el reflejo de una detenninada entidad ideológica, el nacionalismo árabe, que pretendía hacer resurgir la esencia e identidad árabes patentes en todas las manifestaciones culturales de las que dichas revistas han sabido dar cuenta. Y otro aspecto muy sugerente es que a través de ellas se puede apreciar cómo el pensamiento árabe se forma y evoluciona de acuerdo con las circunstancias en las que vive, teniendo en cuenta que la segunda mitad del siglo XX ha sido una época plena en acontecimientos decisivos para ellos.

Pero ha ta los años cincuenta y sesenta los testimonios reflexivos escritos por nativos eran relativamente escasos. La censura obligó a los escritores árabes a publicar fuera de sus fronteras donde la libertad de prensa no estaba coartada por intereses políticos o sociales. 
Por otra parte la transmisión de sus escritos no llegaba a salvar un escollo importante, dado que la lengua árabe no tiene la facilidad de acceso y difusión que otras y que los textos árabes suelen provocar más curiosidad que interés de análisis.

Desde esta perspectiva los intelectuales árabes advirtieron que una gran parte de la bibliografia existente sobre el mundo árabe estaba escrita por pensadores, políticos e intelectuales occidentales. Era decepcionante para ellos encontrarse con más arabistas en las universidades europeas y americanas que en las universidades árabes, y que las bibliotecas foráneas dispusieran de más fuentes y libros especializados que las suyas. En este clima, el conocimiento del mundo árabe contemporáneo estaba limitado a la visión que desde la otra orilla se tenía de ellos ${ }^{1}$.

Desde allí los países árabes constituían un enclave económico y estratégico vital para el resto del mundo desarrollado, y a la vez una fuente de noticias y sucesos políticos y culturales objeto de análisis en países extranjeros. El sirio Yūr Yabūr, a través de una de estas revistas, se lamentó diciendo que los libros publicados fuera de la Patria árabe llegaban a los árabes y que ellos se contentaban con ese estudio más o menos fiel a sus tradiciones. Él dirigía estas preguntas a la comunidad árabe: "¿Será que hasta el conocimiento de nosotros mismos está influido por corrientes extranjeras? ¿acaso nuestra dependencia llega hasta este extremo?"2.

Ante esta desidia cultural, los intelectuales árabes reaccionaron y, conscientes de esta deficiencia, reclamaron la necesidad del reconocimiento propio, de su conciencia, de sus orígenes, de su esencia, y también de sus capacidades para reaccionar ante lo que les rodeaba. Esta labor reflexiva les permitiría dejar de mirarse desde la otra orilla, donde los estereotipos y los prejuicios deforman la verdad, y supondría un enriquecimiento personal y colectivo en todos los ámbitos.

El pensador árabe asume, por tanto, una responsabilidad importante: la toma de conciencia de la realidad, de su pasado y de su presente, y ese conocimiento de aquello que le rodea y de lo que forma parte debe encaminar a toda la comunidad para afrontar un futuro esperanzador. Para alcanzar este propósito se lanza con intensidad a recoger por escrito sus reflexiones y sentimientos, y lo hace utilizando los más variados cauces: la poesía, el teatro, la novela, el relato corto, el ensayo, y también las publicaciones periódicas.

Estas últimas, y en particular las revistas culturales e ideológicas, adquirieron especial relevancia en las décadas siguientes al final del sistema de Mandatos. Su difusión se ha extendido a las esferas intelectuales de Oriente y Occidente, y se han convertido en un

\footnotetext{
${ }^{1}$ Orientalistas anglosajones y franceses, especialmente, y amparados en su superioridad, contribuyeron a crear una imagen deformada de los árabes y del Islam que ha dificultado durante años el entendimiento Oriente-Occidente. Esta cuestión ha sido tratada ampliamente por el palestino E. W. Said en Orientalismo, Madrid, Libertarias, 1990.

${ }^{2}$ Y. Yabūr "Mațluba inšă ' mu'assasa 1-diråsăt al-waḥda al-'arabiyya", al-Ma 'rifa, 127-128, (septiembre-octubre 1972), pp.129-147. La relevancia de este artículo estriba en el reconocimiento del dominio que la conciencia extranjera ejerce sobre la árabe. El Profesor abūr insiste en la necesidad de romper esa influencia para que la conciencia árabe alcance un conocimiento autocrítico que enriquezca y nutra las reflexiones propias, desde el reconocimiento de lo que son y de lo que les rodea.
} 
vehículo de comunicación entre la intelectualidad árabe, en una vía para la reflexión y en el soporte sobre el que los propios árabes pueden hacer llegar a las masas el fruto de sus estudios. Se erigen así en una fuente de inspiración para la comunidad árabe, como reflejo de sus esperanzas y voluntades, en medio de una realidad contingente a la que se enfrentan día a día.

Sobre Occidente también recae una responsabilidad importante: acercarse a esas reflexiones para apreciar con más claridad el contenido y la dimensión del pensamiento árabe contemporáneo. Una buena e imprescindible fuente de información son la revistas culturales e ideológicas, porque este tipo de publicaciones saca a la luz una realidad fluctuante que pone constantemente en la balanza las relaciones internas de la comunidad árabe, que congrega una sociedad heterogénea pero con particularidades comunes que han dado forma a su identidad y esencia. Y al mismo tiempo, esa realidad marca también las relaciones del mundo árabe con el resto del mundo, dentro de un difuso equilibrio acentuado por una relación de amor-odio, de admiración-rechazo, dificil de tratar por separado ${ }^{3}$.

El conocimiento del mundo árabe contemporáneo requiere llegar a la esencia de aquellos con los que hemos tenido, y seguimos mantenido, una relación constante, marcada por enfrentamientos continuos y por una dialéctica en la que han prevalecido las diferencias dentro de dos contextos culturales en el que uno sirve de referencia para definir al otro ${ }^{4}$. Para llegar a ello es necesario primeramente llegar a su conciencia y ser capaces de examinar una realidad que se presenta, se explica y se analiza de modo diametralmente opuesto por ambas partes. La labor que pensadores árabes han realizado en este sentido es lo suficientemente significativa como para que no pase desapercibida.

No pretendo aquí ofrecer una relación detallada de todas las publicaciones periódicas que a lo largo de estos años se han fundado en los diferentes países. árabes. Mi propósito se centra en situarlas dentro de una realidad política y-social determinada, y sobre todo en un contexto ideológico concreto, en ponderar los motivos que generaron su necesidad $\mathbf{y}$ en valorar el grado de importancia que los propios intelectuales árabes les confieren. Pero sí quiero ahora citar algunas de ellas como ejemplos significativos de estos soportes y órganos de comunicación de los que los intelectuales árabes se sirven para hacer llegar sus reflexiones a un público más amplio. Entre ellas destacan la libanesa $a l-A ́ d a b^{5,}$ fundada en

\footnotetext{
' M Nur Edine Afayya marca esta relación como la piedra angular sobre la que ha gravitado el pensamiento y las acciones árabes. É señala que el pensamiento árabe moderno se ha construido recuniendo al "Otro", visto por un lado como el occidente complejo, el enemigo invasor, pero también como el vecino seductor cuyo ejemplo de desarrollo es digno de imitar; en Occidente en el pensamiento árabe moderno, Barcelona, Dossier Daftar 1, Fundación CIBOB, 1995, p.18.

${ }^{4}$ E W. Said, en el libro citado en n.1, toma como referencia del Orientalismo lo que Denys Hay 1lama la idea de Europa: "una noción colectiva que nos define a 'nosotros', europeos, contra todos aquellos no europeos", una noción que manifiesta "la hegemonía europea frente a un oriente retrasado"; opus cit., p. 26

' Un estudio muy interesante sobre las dos tendencias que se manifiestan en la trayectoria de esta revista: la ideológica e infelectual, por un lado, y la propiamente literaria, por otro, es el trabajo de J. A. Pacheco Pan iagua, Literatura, crítica literaria y ensayo en la revista al-Ádiib (1953-1984), Universidad de Granada, Estudios Arabes contemporáneos, 1990.
} 
Beirut en 1953 por el escritor libanés Suhayl Idrīs; la revista egipcia al-Kätib; en Siria sobresale al-Ma 'rifa', marcada por un sello nacionalista de carácter secular y panárabe que alcanzó especial intensidad tras los acontecimientos de 1967; su contenido nos servirá aquí de referencia para ponderar la importancia social, política y sobre todo ideológica de estas publicaciones; también en Siria, Mawāqif, de contenido literario y político y en cuya fundación, entre 1968 y 1969, participó el poeta y ensayista sirio, 'Alī Ahmad Sa'īd, conocido como Adonis. Y por último, dentro del ámbito del Magreb, la revista argelina alAșāla ${ }^{7}$, entre otras.

Tras esta sucinta mención de representativas publicaciones periódicas del panorama intelectual árabe, paso a delimitar el marco político, social e ideológico en el que surgen, pues tanto su temática, como su contenido, así como los colaboradores que asiduamente manifiestan sus ideas, pensamientos y reflexiones a través de sus páginas, están en estrecha relación con esa realidad.

Durante el agitado siglo $\mathrm{XX}$, la conciencia árabe se ha formado en estrecho contacto con Occidente. Diferentes acontecimientos decisivos en el territorio árabe tienen un denominador común: la presencia de lo que se ha dado en llamar "el mundo civilizado". Las consecuencias de los largos años de colonialismo, la formación del Estado de Israel, la intervención de Occidente en la cuestión de Palestina, el monopolio sobre la riqueza petrolífera de los países árabes, necesaria para el desarrollo de la sociedad industrializada, han marcado la personalidad árabe en sus facetas ideológica, social, económica, política y cultural.

La hegemonía y la superioridad que Occidente ha demostrado sobre el mundo árabe no se limita únicamente a la relación colonizador-colonizado, ni dentro de límites económicos, políticos y sociales, sino también, y de modo muy intenso, la presencia de Occidente incidió en un desmán cultural que puso en marcha la necesidad de un resurgimiento nacional en el que estaban implicados todos estos factores. Este resurgimiento (en árabe $b a$ 't ) modeló una conciencia nacionalista marcada por el rechazo hacia la permanencia de la influenciá y la presencia de Occidente en la tierra árabe, y esa conciencia se afianzó en el pueblo tras la formación del Estado de Israel y los sucesivos avances del movimiento sionista ${ }^{8}$.

\footnotetext{
${ }^{6}$ Al-Ma 'rifa editó su primer número en el mes de Abril de 1962, desde entonces y hasta ahora ha contado con el apoyo del gobierno sirio representado por el Ministerio de Cultura y el Consejo Nacional. A lo largo de todos estos años sus páginas han servido en la mayoría de las ocasiones de propaganda política e ideológica del Partido nacionalista en el poder, el Partido Ba 't Árabe Socialista.

${ }^{7}$ Sobre esta revista véase el trabajo de L.W. Deheuvels, Islam et pensée contemporaine en Algerie, La revue alAșāla (1971-1981), Paris, Eds. Du Centre de la Recherches Scientifique, 1991.

${ }^{8}$ El movimiento sionista es la ejecución práctica de los planteamientos teóricos de un auténtico nacionalismo judío. Sobre esta cuestión y sus repercusiones en la conciencia árabe es interesante el estudio de J. Martínez Carreras, El mundo árabe e Israel: el Próximo Oriente en el Siglo XX, Madrid, Itsmo, Colección Fundamentos 114, (2 edición ampliada), 1992.
} 
Pero, la consecución de las sucesivas independencias no significó el logro de las ambiciones árabes, sino que impulsó a estos países hacia un futuro jalonado por una inestabilidad política casi constante, ante las dificultades que supuso ejercer su propia soberanía y contrarrestar la fuerte influencia occidental latente en el espíritu del pueblo árabe. Esta reacción, más allá de suponer la rivalidad entre Oriente y Occidente, fue el índice que midió la lucha de un pueblo por recuperar sus valores, adormecidos durante siglos de dominio, que son fundamento de su esencia. Para la recuperación de esos valores los intelectuales, como portavoces de la conciencia árabe, no permanecen callados y a lo largo de estos dificiles años exponen sus opiniones en libros, artículos, ensayos, relatos cortos, y se sirven también del cine y del teatro, porque cualquier medio era aceptable para que la voz del pueblo árabe se expresara ante la delicada situación.

Por otra parte, la formación del Estado de Israel dentro de la tierra árabe de Palestina se convirtió desde 1948 en un asunto de interés y preocupación general para toda la Nación árabe. Esta nueva intromisión, a la que los intelectuales árabes se refieren como nuevo colonialismo, no quedó relegada a una mera cuestión política, militar y estratégica. Sus repercusiones supusieron, por encírna de todo, un ataque directo al espíritu, a la esencia y al orgullo árabes. En el terreno ideológico esta cuestión llenará de contenido el pensamiento nacionalista árabe, y todas las capas sociales se implicarán en una lucha por la recuperación del orgullo, de los valores y del honor que habían sido dañados.

Sobre estos acontecimientos puntuales, que suponen el colofón de siglos de dominio en los que la sociedad árabe se vio relegada por la preeminencia de fuerzas ajenas a ellos, la ideología nacionalista se levantó para confirmar la existencia y la identidad árabes mediante el resurgimiento de sus capacidades y el despertar de su conciencia. La lucha de esta comunidad se centra desde entonces en romper las cadenas políticas, sociales y económicas que obstaculizaban su autodeterminación y su desarrollo, parapetados detrás de la aparente debilidad de un pueblo sometido.

En relación con esto conviene aclarar que esta larga batalla no se ciñe únicamente a un contexto religioso islámico, aunque éste sea el referente ideológico más claro ${ }^{9}$. Ya a finales del siglo XIX la ideología nacionalista se orientó hacia factores étnicos y culturales en detrimento de la identificación religiosa, como reacción ante el proceso de turquización en el que el factor religioso ligaba a los árabes musulmanes con sus dominadores turcos. El nacionalismo árabe contemporáneo está marcado por el secularismo y el panarabismo. Dentro de sus planteamientos, el Islam se muestra como la fuerza espiritual que integra la herencia cultural árabe, un patrimonio que ha cimentado un carácter y una personalidad propias. El Islam, en el siglo XX, llama al creyente para despertar a un mundo que ha evolucionado y que se manifiesta ajeno al estancamiento de la, en otro tiempo, esplendorosa civilización árabe. En este sentido, en la década de los cincuenta y sesenta, el

\footnotetext{
${ }^{9}$ L Gómez García, Marxismo. Islam e Islamismo: el proyecto de Adil Husayn, Madrid, CantArabia, 1966, p. xvii.
} 
cristiano Michel 'Aflaq se refería al Islam como la fuerza que mueve a los árabes para abrir sus capacidades al progreso deseado ${ }^{10}$.

Tanto la independencia del poder colonial como la formación del Estado de Israel, encendieron el espíritu y la fuerza combativa árabes. La independencia, la libertad, la autodeterminación, el progreso se convirtieron en objetivos preferentes para la construcción de un gran Estado árabe que integrara a toda la Nación árabe. Era el momento preciso para manifestar su arabidad (en arabe 'urüba) y servirse de ella para elaborar una doctrina ideológica con la que se identificaran y cuyos presupuestos teóricos pudieran ser llevados a la práctica para lograr el resurgir de una nueva sociedad árabe moderna fundamentada en vínculos e intereses comunes. Aunque hoy se puede constatar que esa ejecución práctica nunca se ha realizado. En las páginas de al-Ma 'rifa, ūr Șadaqnī confiere al nacionalismo árabe un contenido concreto y preciso:

"Nuestro nacionalismo es nuestra arabidad. Nuestro nacionalismo es progresista y humanístico, porque es un movimiento histórico contemporáneo que defiende la liberación de los árabes y el logro de su realidad natural, que es que ellos son un Estado unido, libre, independiente, democrático y socialista, en el sentido de que el movimiento de este Estado es obligatorio para que los árabes desempeñen su papel en la construcción de una cultura humanística. Confia para ello en la lucha de sus hijos que creen en su pertenencia a él y que se han forjado sobre la idea de que el nacionalismo es una realidad viva y eterna"11.

Ante estos hechos, someramente expuestos, la difusión de revistas de contenido ideológico y cultural en el mundo árabe se convirtió en una cuestión vital. El afianzamiento de una corriente ideológica, como es el nacionalismo árabe, era un asunto que no podía ni debía demorarse, porque tanto su definición precisa como su realidad práctica requerían una acción inmediata. Estas publicaciones fueron la respuesta a la necesidad urgente de elaborar una teoría nacionalista precisa, que supusiera la consolidación de una fuerza ideológica que armonizara las distintas opiniones expresadas y defendidas por los teóricos del nacionalismo.

El objetivo al que aspiraban era ambicioso: una Patria árabe, libre, soberana, independiente y unida. Los intelectuales eran conscientes de que la consecución de grandes logros como éstos había de pasar por pequeñas metas que paso a paso asegurasen el bienestar, la seguridad y el progreso en toda la Nación árabe. Ellos han usado estas publicaciones como un carril material sobre el que plasmar sus reflexiones, dentro de un campo ideológico y cultural que abarca también cuestiones políticas, económicas y sociales. Sus páginas han servido para cubrir la necesidad patriótica y nacionalista de estos intelectuales mediante la transmisión de sus ideas y opiniones para intentar convertirse en intermediarios entre las masas y los gobernantes. Al mismo tiempo, estas revistas constituyen un puente de unión entre la intelectualidad local, nacional e internacional. Pero,

\footnotetext{
${ }^{10}$ S. G. Haim, Arab Nationalism: an Anthology, Berkeley \& Los Ángeles, University of California Press, 1964, p. 64. En los años cuarenta M. 'Aflaq fundó junto, con el musulmán sunní Salāh al-Dīn al-Bițār, el Partido Ba"t Árabe Socialista en Siria. Este Partido se ha mantenido en el poder desde 1963 y ha contado en sus filas con uno de los líderes árabes más carismáticos, Ḥăfiz al-Asad (1970-2000), apodado el León de Damasco.

11 . ȘadaqnT, "Qawmiyyatu-nā curūbatu-nā”, "al-Ma'rifa, 169, (marzo 1976), p. 16.
} 
a través de sus páginas, Oriente y Occidente también han sido testigos de cómo estas cuestiones se han ido desvirtuando a medida que los acontecimientos y las circunstancias cambiaban.

El pensamiento nacionalista se convirtió entonces en el eje ideológico de las revistas culturales árabes. A través de ellas los intelectuales volvieron la vista atrás, hacia su valiosa herencia cultural, y al hacerlo mostraron a la Nación árabe que su situación actual contrastaba con su pasado esplendor. Esto se convirtió en el revulsivo que dirigió a la comunidad árabe hacia un nacionalismo progresista que recurre con frecuencia a ese brillante pasado histórico, común a toda la comunidad árabe. Pero no se pretendía con ello volver atrás y anclarse nuevamente en un ayer que, aunque esplendoroso, ya pasó, sino avanzar hacia adelante impulsados por los ricos valores y los fuertes pilares que esta cultura posee. Fu'ad al-Sayib, Jefe de Redacción de la revista Siria, insistía en esta idea:

"Tenemos que admitir el cambio natural del pasado para que podamos vivir en el siglo XX y no en el siglo XVI, bajo el rigor de la verdad, con esfuerzo, dedicación y amor a la vida y con un deseo de supervivencia"12.

Este último siglo ha sido próvido en cambios para el mundo árabe y el dominio occidental ha tenido mucho que ver en ello. Las mutaciones que la conciencia árabe ha sufrido han aclarado y han puesto de manifiesto cambios culturales anteriores. Estas circunstancias generaron en los intelectuales la necesidad de acudir a testimonios reflexivos que han discurrido a través de la propia evaluación que ha calibrado, dentro de unos parámetros concretos, la capacidad de renovación de la conciencia árabe a tenor de los acontecimientos que le toca vivir.

A través de sus escritos, constatamos que el desarrollo y la evolución del pensamiento árabe contemporáneo se han definido a través de su propia realidad. Las experiencias vividas han configurado una conciencia determinada que singulariza al hombre árabe como miembro de una comunidad particular con unas características propias que concretan su personalidad. Estas marcas distintivas, entre las que sobresalen la lengua y la historia comunes, constituyen su esencia y su reconocimiento confirma la identidad de los individuos que forman parte de esta comunidad.

El principal presupuesto de los teóricos del nacionalismo era que los árabes se reconocieran a sí mismos para afrontar un necesario renacimiento cultural, social, político y económico, que a partir de la admiración por su pasado histórico supiera reconocer su realidad presente y reaccionar ante ella adquiriendo el compromiso de construir su futuro en una sociedad progresista y moderna. En este sentido la importancia de estas publicaciones radicaba en que los textos de los intelectuales árabes transmitidos a través de sus páginas mostraban la realidad interior árabe, su esencia y su identidad, dando forma a una ideología particular que pretendía dar respuesta a las esperanzas y a los deseos del pueblo árabe subyugado durante mucho tiempo a los deseos de fuerzas ajenas a ellos.

Ante esto, la necesidad de difundir revistas periódicas de contenido ideológico y cultural estuyo motivada en muchos casos por la urgencia de crear un órgano de difusión

\footnotetext{
${ }^{12}$ F. al- ayib, al-Ma "nifa, 1, (abril 1962), p. 9.
} 
autóctono, enriquecido con el trabajo de sus propios pensadores, artistas, científicos y literatos. La falta de testimonios reflexivos compuestos por nativos desató esta necesidad, y los intelectuales árabes recurrieron a ellas como un medio idóneo de comunicación entre los propios árabes, con la finalidad, no sólo de reconocerse a sí mismos, sino también de dar a conocer su pensamiento al resto del mundo.

De este modo se daba vía libre a la publicación de distintas ideas sobre diferentes campos de la cultura, en los que se incluye la literatura, el teatro, el cine, el arte, la ciencia, sin dejar de lado el intrincado asunto de la política árabe. Pero no se trata únicamente de una necesidad intelectual, sino también ideológica y espiritual. Estas revistas, a través de las plumas de sus colaboradores, asumen con el contenido de sus escritos una doble responsabilidad: ideológica y cultural. En este sentido el doctor Sukrī Fayșal defiende su concepción de la escritura no como una mera actividad personal, sino como respuesta a una necesidad patriótica y nacionalista, al mismo tiempo que sirve a una necesidad espiritual e ideológica ${ }^{13}$. En respuesta a ello estas publicaciones amplían sus contenidos y abarcan todas las ramas del conocimiento humano, cuyo cultivo es imprescindible en el camino del progreso y el desarrollo de cualquier sociedad.

Los temas propuestos se enmarcan entonces, y sobre todo en las décadas de los sesenta y setenta, en el contexto de un nacionalismo árabe avanzado, moderno, acorde con la época y que ayude a fortalecer su sociedad en relación con otras más progresistas, gracias a las cuales también avanza, se desarrolla y se siente orgullosa de sus propios logros. Este nacionalismo tiene la impronta de la libertad y de sus fines, evolución y progreso.

Estos hitos dirigieron a los colaboradores de las distintas revistas a orientar sus reflexiones en dos direcciones: miran por una parte hacia sí mismos, pero también hacia Occidente, a sabiendas de que su propio desarrollo no estriba en vivir de espaldas a él sino en la capacidad de dar y tomar a un tiempo, porque no dudan de que la conciencia árabe contemporánea se ha formado en estrecho contacto con la otra orilla. Esta relación, desde el punto de vista árabe, ha sido un factor de enriquecimiento cultural, social y económico, pero también un elemento desintegrador que ha generado profundas diferencias entre los países árabes con un nivel de desarrollo desigual.

Las revistas culturales árabes abrieron sus puertas, y aún hoy lo siguen haciendo, a pensadores, literatos, artistas y científicos, y se han convertido en un rico y variado testimonio de las capacidades humanas. Han potenciado el diálogo y son el canal por el que se manifiestan las esperanzas, los deseos y las ambiciones árabes, pero también sus derrotas, preocupaciones y frustraciones. Sus páginas sirven, la mayoría de las veces, de instrumento propagandístico para la autoridad política dominante, otras de foro en el que manifestar denuncias, criticando lo ocurrido hasta entonces, pero sobre todo han sido un canal expresivo destinado a resaltar el espíritu de la esencia árabe. Su vinculación con la realidad contribuye de modo muy particular al reconocimiento de la conciencia del hombre árabe contemporáneo.

13 S. Fayșal, "Rihla al-waḥda fî-l-ḍamĩr al-‘arabr”, al-Ma 'rifa, 127-128 (septiembre-octubre 1972), p. 58. 
Los hombres que escriben en ellas, han sido, en un número elevado, testigos del dominio colonialista y de sus consecuencias, y sus reflexiones y sentimientos hunden sus raíces en las experiencias vividas. Sus trabajos en prosa o en verso, sus artículos, libros, ensayos, etc., reflejan los sentimientos del pueblo árabe, y a través de estas publicaciones se convierten en una literatura viva, reflejo de su arabidad. Ello los convierte en documentos imprescindibles para el conocimiento del mundo árabe actual.

En definitiva, y para concluir, este tipo de publicaciones, de marcada tendencia nacionalista, pretendían ser el testimonio palpable de la lucha de la Nación árabe. Las reflexiones de los intelectuales pasaban por un reconocimiento propio que les hacía reflexionar y profupdizar en su esencia, en su voluntad y en sus capacidades para afrontar los desafios a los que se enfrentaban cada día. Pero su esfuerzo se ha convertido finalmente en una vacua retórica ideológica y política que no ha sabido pasar de la elaboración teórica a la realización práctica. Los objetivos de mayor peso aún no se han cumplido, y cierto sentimiento de fracaso prevalece nuevamente en el mundo árabe en general, consciente de la situación actual, comprometida y dificil. Unos se resignan, otros actúan desde el exterior, y otros más atrevidos intentan cambiar su sociedad desde dentro, exponiéndose a la dura censura del integrismo, surgido como reacción ante lo que ellos ven como el fracaso del proyecto de desarrollo a todos los niveles. 